THE annexin lipocortin 1 is reported to mediate some anti-inflammatory effects of glucocorticoids, but the mechanisms of this mediation are incompletely understood. The involvement of lipocortin 1 in glucocorticoid

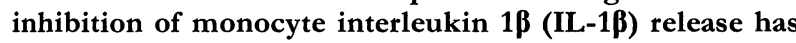
been investigated. Treatment of peripheral blood monocytes with $2 \mu \mathrm{g} / \mathrm{ml}$ lipopolysaccharide potently increased IL-1 $\beta$ release $(p=0.001)$ and dexamethasone $\left(10^{-7} \mathrm{M}\right)$ significantly reduced both resting and stimulated IL-1 $\beta$ release $(p=0.009)$. A neutralizing monoclonal antibody to lipocortin $1(0.5-50.0 \mu \mathrm{g} / \mathrm{ml})$ was unable to inhibit this effect and recombinant lipocortin $1\left(2 \times 10^{-6} \mathrm{M}\right)$ and 188aa lipocortin 1 fragment $\left(10^{-8}-10^{-6} M\right)$ had no effect. It is concluded that lipocortin 1 is not involved in the inhibition of monocyte IL-1ß release by glucocorticoids.

Key words: Glucocorticoid, Interleukin 1, Lipocortin 1 (annexin 1), Monocyte

\section{Lack of involvement of lipocortin 1 in dexamethasone suppression of IL-1 release}

\author{
E. F. Morand ${ }^{\mathrm{CA}, *}$, D. Rickard and \\ N. J. Goulding
}

Bath Institute for Rheumatic Diseases, Trim Bridge, Bath, BA1 1HD, UK

* Present Address: Rheumatology Unit, Monash Medical Centre, Locked Bag No. 29, Clayton, 3168, Australia

${ }^{\mathrm{CA}}$ Corresponding Author

\section{Introduction}

Lipocortin 1 (annexin 1) is a member of the annexin family of calcium-phospholipid binding proteins. $^{1,2}$ The production of lipocortin 1 is induced by glucocorticoids in a number of systems, ${ }^{3-6}$ including human peripheral blood mononuclear cells after in vivo exposure to glucocorticoids. ${ }^{7}$ Lipocortin 1 has been demonstrated to have a number of anti-inflammatory actions in both in vitro and in vivo systems, ${ }^{8-16}$ but the influence of this protein on cytokine production is unknown. The anti-inflammatory activity of lipocortin 1 in vivo has yet to be fully explained in terms of specific actions.

Interleukin-1 (IL-1) is a potent pro-inflammatory cytokine which is produced in a wide range of tissues including tissue macrophages, peripheral blood monocytes, brain, synovium, lung, gut, and bone. ${ }^{17}$ It is involved in the mediation of inflammation in a diverse list of conditions including rheumatoid arthritis. ${ }^{18,19}$ The production of IL-1 in inflammatory tissue sites is under the control of regulatory and counter-regulatory systems. The major inhibitors of IL-1 production are the glucocorticoids, and it is now well established that dexamethasone inhibits the induction of monocyte IL-1 release by bacterial lipopolysaccharide (LPS) in a dose dependent fashion. ${ }^{20}$ The mechanisms of this inhibition are complex and include translational, transcriptional and post-transcriptional events. ${ }^{21-23}$ An attractive explanation for some of the anti-inflammatory actions of lipocortin 1 would be the inhibition of IL-1 release or activity, and the possibility that lipocortin 1 is involved in the suppression by glucocorticoids of IL- $1 \beta$ release is supported by several observations. First, glucocorticoid inhibition of IL-1 release in some in vitro settings is abrogated by cycloheximide, an inhibitor of protein synthesis. $^{24}$ Secondly, nuclear run-off studies suggest that glucocorticoid inhibition of the early phases of monocyte IL- $1 \beta$ release may occur without effects on transcription of the IL- $1 \beta$ gene. ${ }^{22}$ The mechanism of transport of IL- $1 \beta$ from the cytoplasm to the extracellular environment is not known, but IL- $1 \beta$ does not appear to have a signal peptide and is not transported via the Golgi apparatus. ${ }^{25}$ Annexins, often cytoskeletal associated, have been reported in preliminary studies to be implicated in cell membrane vesicle formation, exocytosis, and secretion. ${ }^{26,27}$

The role of lipocortin 1 in the inhibition by dexamethasone of IL- $1 \beta$ release from peripheral blood monocytes has been investigated using recombinant lipocortin 1 , a bioactive lipocortin 1 fragment, and a neutralizing antibody to lipocortin 1. It is reported that none of these agents impact on LPS induced monocyte IL- $1 \beta$ release, or the suppression of it by glucocorticoids, and the authors conclude that lipocortin 1 is not involved in this action of glucocorticoids.

\section{Materials and Methods}

Reagents: Cells were cultured in RPMI 1640 (Gibco, UK) supplemented with penicillin, streptomycin and L-glutamine (Gibco, UK) and with $10 \%$ heat inactivated charcoal stripped foetal calf serum (Flow, ICN Laboratories, UK). Cell washes were performed with calcium and magnesium-free 
phosphate buffered saline with $0.16 \%$ glucose (PBSG). Refolded recombinant human lipocortin 1 (rhLC1) and a neutralizing mouse monoclonal antibody to human LC1 (1A) were kindly provided by Dr J. Browning (Biogen, Cambridge, MA). A bioactive $\mathrm{N}$-terminal 188 amino acid fragment of lipocortin 1 (1-188aa) was kindly provided by Dr F. Carey, ICI Pharmaceuticals, Cheshire, UK. IL- $1 \beta$ ELISA were purchased from Cascade Biochem (Reading, UK). Dexamethasone and LPS (Escherichia coli, serotype 055:B5 lipopolysaccharide) were purchased from Sigma (St. Louis, MO).

Monocyte separation: Peripheral venous blood was drawn from healthy volunteers into heparinized containers and diluted 1:1 with PBSG. Mononuclear cells were separated by centrifugation on a Histopaque 1077 (Sigma, St Louis, MO) density gradient for $30 \mathrm{~min}$ at $400 \times \mathrm{g}$, washed in $\mathrm{PBSG}$, and resuspended at $5 \times 10^{6}$ cells $/ \mathrm{ml}$ in culture medium with $10 \%$ FCS. Monocytes in this suspension were allowed to adhere to $10 \mathrm{~cm}$ Petri dishes (Costar, Cambridge, MA) for $60 \mathrm{~min}$ at $37^{\circ} \mathrm{C}$ and $5 \% \mathrm{CO}_{2}$ in a humidified incubator. After nonadherent cells were removed by vigorous pipetting with medium, adherent cells were removed by gentle scraping with a rubber 'policeman' and washing with cold PBSG. Adherent cells were $<10 \%$ CD3 positive by flow cytometric analysis.

Cell culture: Monocytes were cultured in $1 \times 10^{6}$ cell aliquots. Neutralizing antibody to lipocortin 1 $(0.5-50 \mu \mathrm{g} / \mathrm{ml})$, control antibody P3 $(50 \mu \mathrm{g} / \mathrm{ml})$, rhLC1 $\left(2 \times 10^{-6} \mathrm{M}\right)$ or 1-188aa fragment $\left(2 \times 10^{-6}\right.$ to $\left.2 \times 10^{-8} \mathrm{M}\right)$ were incubated with monocytes for $2 \mathrm{~h}$ in 96 -well plates at $37^{\circ} \mathrm{C}$ and $5 \% \mathrm{CO}_{2}$ in a humidified incubator. Cells were then resuspended into $1 \mathrm{ml}$ of medium in 24-well tissue culture plates (Costar, Cambridge, MA) and LPS $2 \mu \mathrm{g} / \mathrm{ml}$ and/or dexamethasone $10^{-7} \mathrm{M}$ added. Cells were cultured for $48 \mathrm{~h}$ at $37^{\circ} \mathrm{C}$ and $5 \% \mathrm{CO}_{2}$ in a humidified incubator and viability at this time was $>95 \%$.

IL-1 $\beta$ assay: Culture supernatants were obtained by centrifuging plates at $400 \times \boldsymbol{g}$ for $5 \mathrm{~min}$ and careful aspiration. Supernatants contained $<1 \times 10^{4}$ cells $/ \mathrm{ml}$. Supernatants were stored at $-70^{\circ} \mathrm{C}$ until assay. IL- $1 \beta$ ELISA were performed according to the manufacturer's instructions and had a sensitivity of $1 \mathrm{pg} / \mathrm{ml}$.

Statistical analysis: Supernatant IL-1 $\beta$ levels were compared using the Wilcoxon signed ranks test, or Mann Whitney $U$ test when the number of pairs was less than six. Values of $p$ less than 0.05 were regarded as statistically significant.

\section{Results}

IL- $1 \beta$ was detected in the supernatants of untreated monocytes (mean 623, S.E.M. $122 \mathrm{pg} / \mathrm{ml}, n=13$ ).
In all experiments, LPS $2 \mu \mathrm{g} / \mathrm{ml}$ induced significant increases in supernatant IL- $1 \beta$ concentration (mean 2188, S.E.M. $298 \mathrm{pg} / \mathrm{ml}, \quad p=0.001, \quad n=13)$. Dexamethasone potently inhibited LPS induced IL-1 $\beta$ release in all experiments (mean 666, S.E.M. $94 \mathrm{pg} / \mathrm{ml}, p=0.009$, LPS vs LPS plus dexamethasone, $n=13$ ) (Figs 1-3). Dexamethasone $10^{-7} \mathrm{M}$ also inhibited the levels of IL- $1 \beta$ in the supernatants of non-LPS treated monocytes (mean 291, S.E.M. $85 \mathrm{pg} / \mathrm{ml}, p=0.009$, dexamethasone treated $v s$ untreated, $n=7$, Fig. 1 and 2). Pretreatment of monocytes with neutralizing antibody to lipocortin 1 in doses of $0.5-50.0 \mu \mathrm{g} / \mathrm{ml}$ had no effect on the inhibitory action of dexamethasone $10^{-7} \mathrm{M}$ on IL- $1 \beta$ release (Fig. 1). Pretreatment of monocytes with rhLC1 $2 \times 10^{-6} \mathrm{M}$ had no suppressive effect on non-LPS treated monocyte IL- $1 \beta$ release, nor on the increase in IL- $1 \beta$ release induced by LPS (Fig. 2). Pretreatment

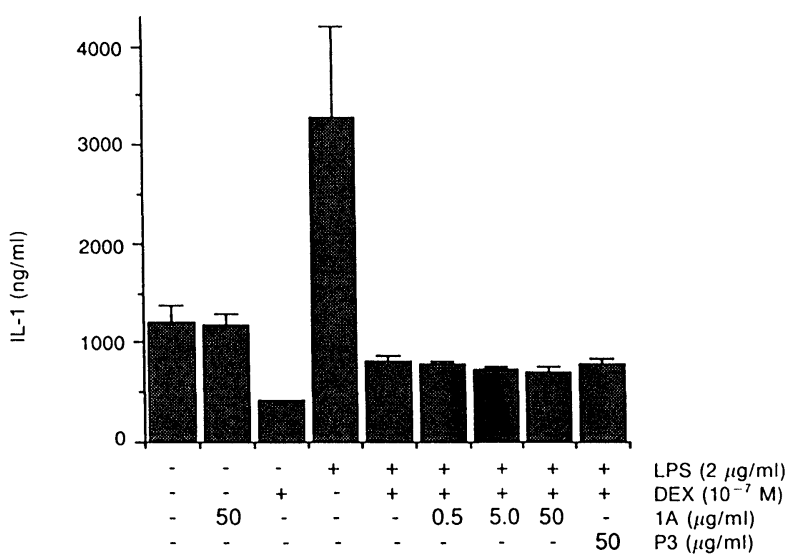

FIG. 1. Monocyte IL-1 $\beta$ release: effects of neutralizing antibody to lipocortin 1. Peripheral blood monocytes were cultured for $48 \mathrm{~h}$ in the presence of bacterial lipopolysaccharide $2 \mu \mathrm{g} / \mathrm{ml}$ (LPS), dexamethasone $10^{-7} \mathrm{M}$ (DEX), anti-lipocortin 1 antibody $0.5-50 \mu \mathrm{g} / \mathrm{ml}(1 \mathrm{~A})$ and/or control antibody (P3), and the IL-1 $\beta$ concentration in culture supernatants measured by ELISA. LPS induced a marked increase in IL-1 $\beta$ release $(p=0.001)$ which was suppressed by dexamethasone $(p=0.009)$. Dexamethasone also inhibited resting (non-LPS-treated) monocyte IL- $1 \beta$ release $(p=0.009)$. Anti-lipocortin antibody had no effect on the ability of DEX to suppress this response.

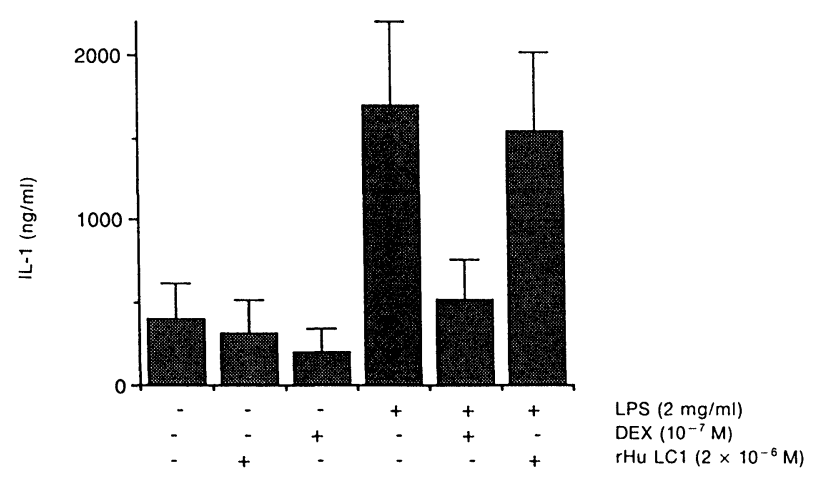

FIG. 2. Monocyte IL- $1 \beta$ release: effects of recombinant human lipocortin 1. Peripheral blood monocytes were cultured for $48 \mathrm{~h}$ in the presence of LPS $2 \mu \mathrm{g} / \mathrm{ml}$, dexamethasone $10^{-7} \mathrm{M}$ (DEX), and recombinant human lipocortin $12 \times 10^{-6} \mathrm{M}(\mathrm{rHLC}-1)$ and the IL-1 $\beta$ concentration in culture supernatants measured by ELISA. rhLC-1 did not reproduce the inhibition of monocyte IL-1 $\beta$ release observed with dexamethasone. 


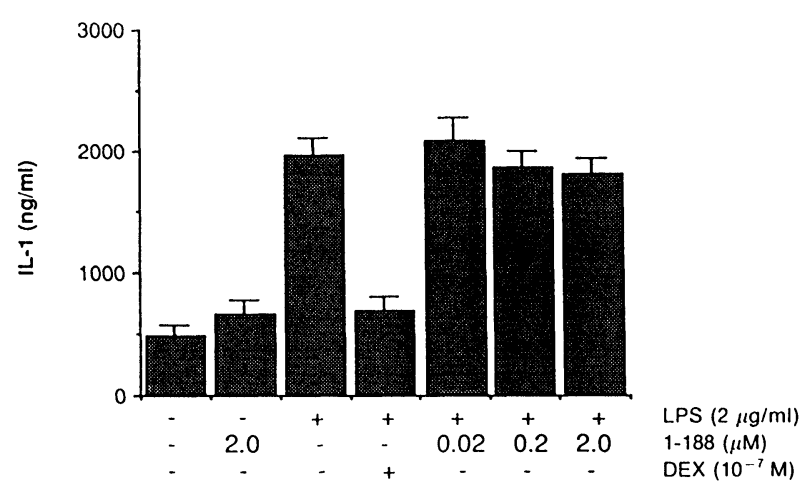

FIG. 3. Monocyte IL-1 $\beta$ release: effects of 188aa N-terminal fragment of lipocortin 1. Peripheral blood monocytes were cultured for $48 \mathrm{~h}$ in the presence of LPS $2 \mu \mathrm{g} / \mathrm{ml}$, dexamethasone $10^{-7} \mathrm{M}$ (DEX), and $\mathrm{N}$-terminal 188 amino acid lipocortin 1 fragment $2 \times 10^{-8}-2 \times 10^{-6} \mathrm{M}(1-188)$, and the IL-1 $\beta$ concentration in culture supernatants measured by ELISA. 1-188 did not reproduce the inhibition of monocyte IL-1 $\beta$ release observed with dexamethasone.

of monocytes with the 1-188aa lipocortin 1 fragment at concentrations of $2 \times 10^{-8} \mathrm{M}$ to $2 \times 10^{-6} \mathrm{M}$ similarly had no effect on untreated or LPS treated monocyte IL-1 $\beta$ release (Fig. 3).

\section{Discussion}

Evidence from animal models suggests that lipocortin 1, a member of the annexin family of calcium-phospholipid binding proteins, may be a mediator of some of the anti-inflammatory actions of glucocorticoids. ${ }^{1,2}$ The production of lipocortin 1 has been shown to be induced by glucocorticoids in a number of in vitro and in vivo studies. ${ }^{3-7}$ Additionally, lipocortin 1 has been demonstrated to mimic many in vitro actions of glucocorticoids, including inhibition of natural killer cell activity and antibody dependent cell-mediated cytotoxicity, inhibition of reaction oxygen species generation, and inhibition of prostaglandin and thromboxane release. ${ }^{8-10}$ Exogenous lipocortin 1 and bioactive fragments of lipocortin 1 have, furthermore, been demonstrated to exert anti-inflammatory activity in vivo in a number of animal models of inflammation. ${ }^{11-16}$

The results reported in this paper do not support a role for lipocortin 1 in the suppression of IL- $1 \beta$ release by monocytes. Lipocortin 1 may, however, be involved in the mediation of glucocorticoid inhibition of the actions of IL-1, rather than its production or release. A model for this hypothesis exists in the hypothalamo-pituitary-adrenal axis. IL-1 is produced in the pituitary, IL-1 receptors have been demonstrated in pituitary cell cultures, and circulating IL-1 is active in the pituitary where it is involved in the regulation of the hypothalamopituitary-adrenal axis response to inflammation. ${ }^{28-30}$ Lipocortin 1 has been demonstrated in the rat pituitary, ${ }^{31}$ and intracerebroventricular (i.c.v.) infu- sion of lipocortin 1 or the 1-188aa peptide fragment of lipocortin 1 is associated with a reduction in the pyrogenic response to i.c.v. IL-1, ${ }^{14}$ strongly suggesting that lipocortin 1 can directly inhibit actions of IL-1. In addition, IL-1 increases phospholipase A2 (PLA2) activity and leukocyte prostaglandin release, ${ }^{17,32}$ while lipocortin 1 reduces the production of prostaglandins via inhibition of PLA2 activity, probably by binding to its substrate. ${ }^{33}$ In contrast, prostaglandins have been reported to inhibit the production of IL-1 by monocytes, possibly as part of an autocrine feedback network. ${ }^{32,34}$ Potential effects of lipocortin 1 on IL-1 release or action may be reversed by its effect on prostaglandins. These suggestions of an interaction of IL-1 and lipocortin 1 are of course conjectural, and further research on the area of annexin-cytokine interactions is needed.

In summary, lipocortin 1 is a glucocorticoid induced protein whose anti-inflammatory activity remains incompletely understood. A possible mechanism of action of lipocortin 1 is the inhibition of IL-1 release, possibly through effects on its secretion. In studies with recombinant lipocortin 1 , a bioactive lipocortin 1 fragment, and neutralizing antibodies to lipocortin 1, the authors have been unable to demonstrate evidence that lipocortin 1 is involved in the suppression by glucocorticoids of the release of $\mathrm{IL}-1 \beta$ by human peripheral blood monocytes.

\section{References}

1. Peers SH, Flower RJ. The role of lipocortin in corticosteroid actions. Ann Rev Respir Dis 1990; 141: S18-S21.

2. Flower RJ. Lipocortin. Prog Clin Biol Res 1990; 349: 11-25.

3. Ambrose MP, Hunninghake GW. Corticosteroids increase lipocortin 1 in alveolar epithelial cells. Am J Respir Cell Mol Biol 1990; 3: 349-353.

4. Wong WT, Frost SC, Nick HS. Protein-synthesis-dependent induction of annexin I by glucocorticoid. Biochem J 1991; 275: 313-319.

5. Solito E, Raugei G, Melli M, Parente L. Dexamethasone induces the expression of the mRNA of lipocortin 1 and 2 and the release of lipocortin 1 and 5 in differentiated, but not undifferentiated U-937 cells. FEBS Let 1991; 291: 238-244.

6. Ambrose MP, Hunninghake GW. Corticosteroids increase lipocortin 1 in BAL fluid from normal individuals and patients with lung disease. $J A p p$ Physiol 1990; 68: 1668-1671.

7. Goulding NJ, Godolphin JL, Sharland PR, et al. Anti-inflammatory lipocortin 1 production by peripheral blood leucocytes in response to hydrocortisone. Lancet 1990; 335: 1416-1418.

8. Hattori T, Hirata F, Hoffman T, Hizuta A, Herberman RB. Inhibition of human natural killer (NK) activity and antibody dependent cellula cytotoxicity (ADCC) by lipomodulin, a phospholipase inhibitor protein. $J$ Immunol 1983; 131: 662-665.

9. Cirino G, Flower R J, Browning JL, Sinclair LK, Pepinsky RB. Recombinan human lipocortin 1 inhibits thromboxane release from guinea-pig isolated perfused lung. Nature 1987; 328: 270-272.

10. Maridonneau-Parini I, Errasfa M, Russo-Marie F. Inhibition of $\mathrm{O}_{2}^{-}$ generation by dexamethasone is mimicked by lipocortin $\mathrm{I}$ in alveolar macrophages. I Clin Invest 1989; 83: 1936-1940.

11. Errasfa M, Russo-Marie F. A purified lipocortin shares the anti-inflammatory effect of glucocorticosteroids in vivo in mice. Br J Pharmacol 1989; 97 1051-1058.

12. Errasfa M, Rothhut B, Russo-Marie F. Phospholipase A2 inhibitory activity in thymocytes of dexamethasone-treated mice-Possible implication of lipocortins. Biochem Biophys Res Commun 1989; 159: 53-60.

13. Relton JK, Strijbos PJLM, O'Shaughnessy CT, et al. Lipocortin-1 is an endogenous inhibitor of ischemic damage in the rat brain. J Exp Med 1991, 174: 305-310.

14. Carey F, Forder R, Edge MD, et al. Lipocortin-1 fragment modifies the pyrogenic actions of cytokines in rats. Am J Physiol 1990; 259: R266-R269. 
15. Perretti M, Flower RJ. Lipocortin-1 inhibits the neutrophil infiltration elicited by interleukin-1 in the mouse air pouch. Br J Pharmacol 1992; (in press)

16. Cirino G, Peers SH, Flower RJ, Browning JL, Pepinsky RB. Human recombinant lipocortin 1 has acute local anti-inflammatory properties in the rat paw edema test. Proc Natl Acad Sci USA 1989; 86: 3428-3432.

17. Dinarello CA. Biology of interleukin 1.FASEB J 1988; 2: 108-115.

18. Arend WP, Dayer J-M. Cytokines and cytokine inhibitors or antagonists in rheumatoid arthritis. Artbritis Rheum 1990; 33: 305-315.

19. Kirkham B. Interleukin-1, immune activation pathways, and different mechanisms in osteoarthritis and rheumatoid arthritis. Ann Rheum Dis 1991, 50: $395-400$.

20. Uehara A, Kohda H, Sekiya C, Takasugi Y, Namiki M. Inhibition of interleukin-1 beta release from cultured human peripheral blood mononuclear cells by prednisolone. Experientia 1989; 45: 166-167.

21. Knudsen PJ, Dinarello CA, Strom TB. Glucocorticoids inhibit transcriptional and post-transcriptional expression of interleukin 1 in U937. J Immunol 1987; 139: 4129-4134.

22. Kern JA, Lamb RJ, Reed JC, Daniele RP, Nowell PC. Dexamethasone inhibition of interleukin 1 beta production by human monocytes. Posttranscriptional mechanisms. J Clin Invest 1988; 81: 237-244.

23. Lew W, Oppenheim JJ, Matsushima K. Analysis of the suppression of IL-1 $1 \alpha$ and IL- $1 \beta$ production in human peripheral blood mononuclear adherent cells by a glucocorticoid hormone. I Immunol 1988; 140: 1895-1902.

24. Nishida T, Nakai S, Kawakami T, Aihara K, Nishino H, Hirai Y Dexamethasone regulation of the expression of cytokine mRNAs induced by interleukin-1 in the astrocytoma cell line U373MG. FEBS $J 1989$ 243: $25-29$.

25. Dinarello CA. Interleukin 1 and interleukin 1 antagonists. Blood 1991; 77: $1627-1652$.

26. Geisow MJ, Ali SM, Boustead C, Burgoyne RD, Taylor WR, Walker JH Structures and functions of a supergene family of calcium and phospholipid binding proteins. Prog Clin Biol Res 1991; 349: 111-121.

27. Zaks WJ, Creutz CE. Evaluation of the annexins as potential mediators of membrane fusion in exocytosis. J Bioenerg Biomembr 1990; 22: 97-120.
28. Spangelo BL, MacLeod RM. The role of immunopeptides in the regulation of anterior pituitary hormone release.TEM 1990; 2: 409-410.

29. Webster EL, Tracey DE, De Souza EB. Upregulation of interleukinreceptors in mouse AtT-20 pituitary tumour cells following treatment with corticotropin-releasing factor. Endocrinology 1991; 129: 2796-2798.

30. Saperstein A, Brand $\mathrm{H}$, Audhya $\mathrm{T}$, et al. Interleukin 1 beta mediates stress-induced immunosuppression via corticotropin-releasing factor. En docrinology 1992; 130: 152-158.

31. Strijbos PJLM, Tilders FJH, Carey F, Forder R, Rothwell NJ. Localization of immunoreactive lipocortin-1 in the brain and pituitary gland of the rat Effects of adrenalectomy, dexamethasone and colchicine treatment. Brain Res 1991.

32. Hopkins SJ. Cytokines and eicosanoids in rheumatic diseases. Ann Rbeum Dis 1990; 49: 207-211

33. Davidson FF, Dennis EA, Powell M, Glenney JR Jr. Inhibition of phospholipase A2 by "lipocortins" and calpactins. An effect of binding to substrate phospholipids. J Biol Chem 1987; 262: 1698-1705.

34. Knudsen PJ, Dinarello CA, Strom TB. Prostaglandins posttranscriptionally inhibit monocyte expression of interleukin-1 activity by increasing intracellular cyclic adenosine monophosphate. J Immunol 1986; 137 3189-3194.

ACKNOWLEDGEMENTS. E.F.M. is the recipient of a Michael Mason Fellowship, Arthritis Foundation of Australia. N.J.G. thanks the Arthritis Research Council, UK for support.

Received 24 November 1992;

accepted 1 December 1992 


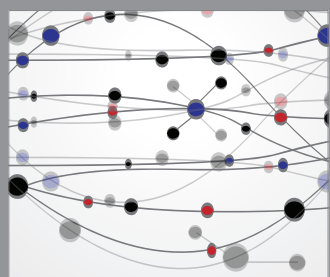

The Scientific World Journal
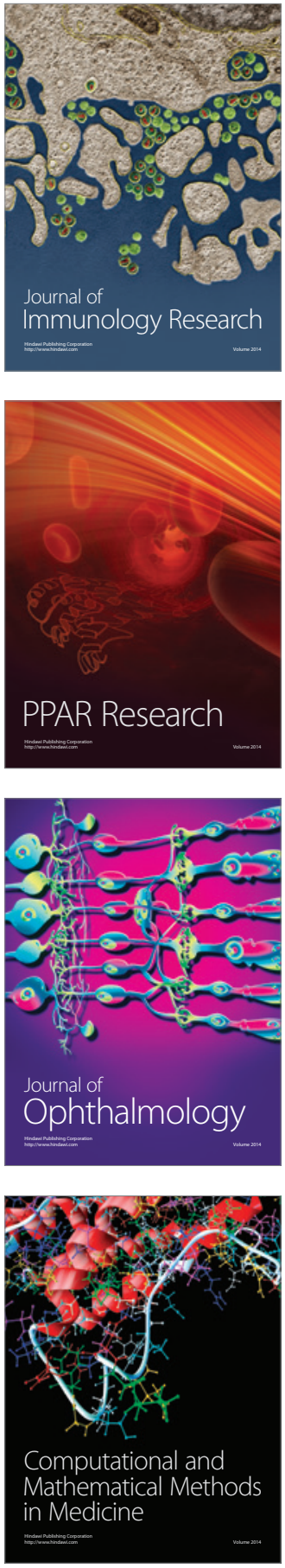

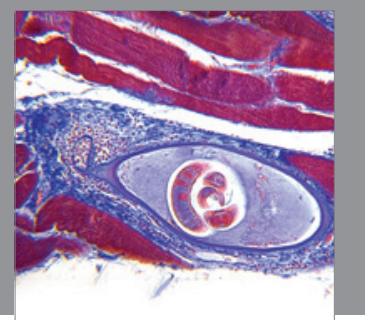

Gastroenterology

Research and Practice
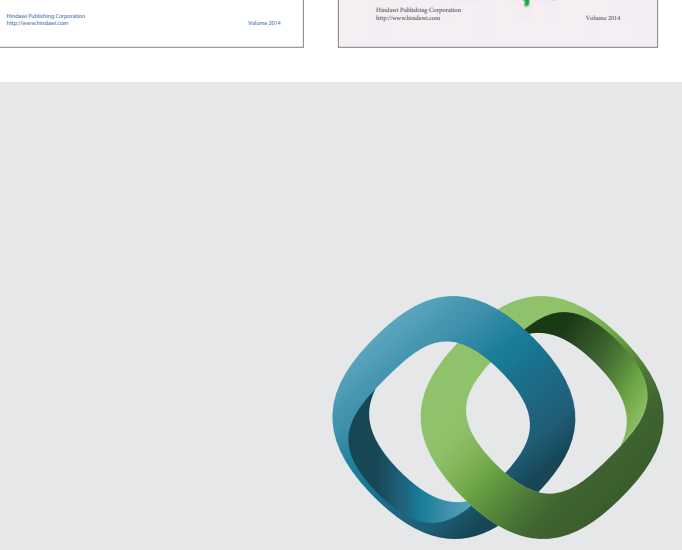

\section{Hindawi}

Submit your manuscripts at

http://www.hindawi.com
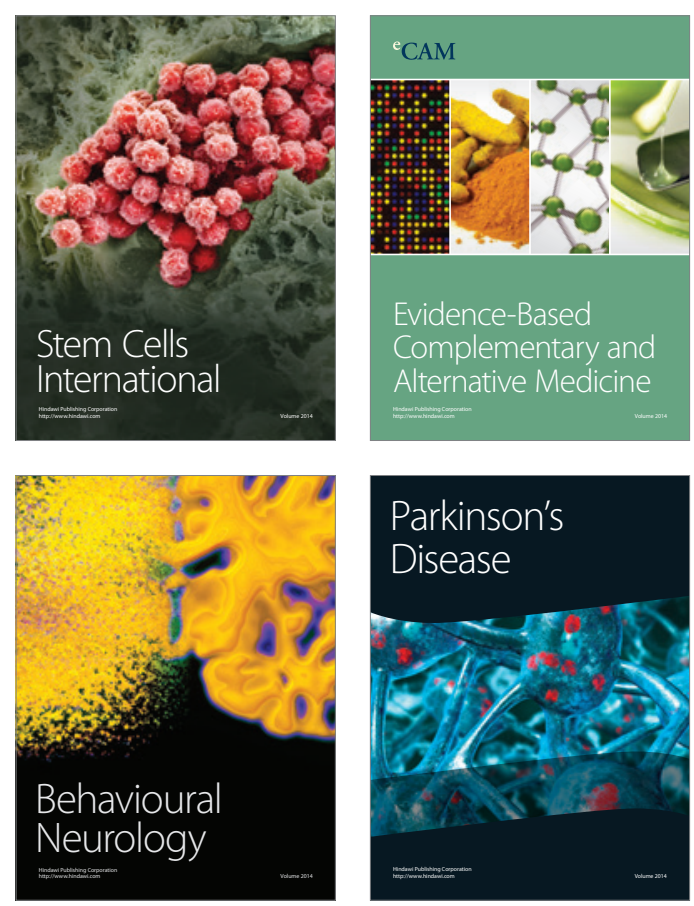

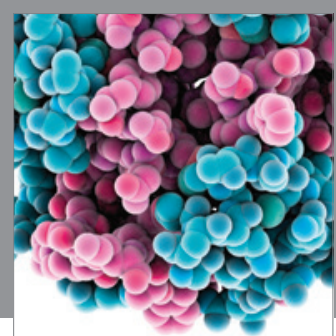

Journal of
Diabetes Research

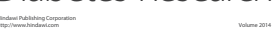

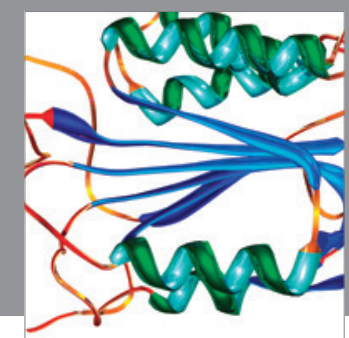

Disease Markers
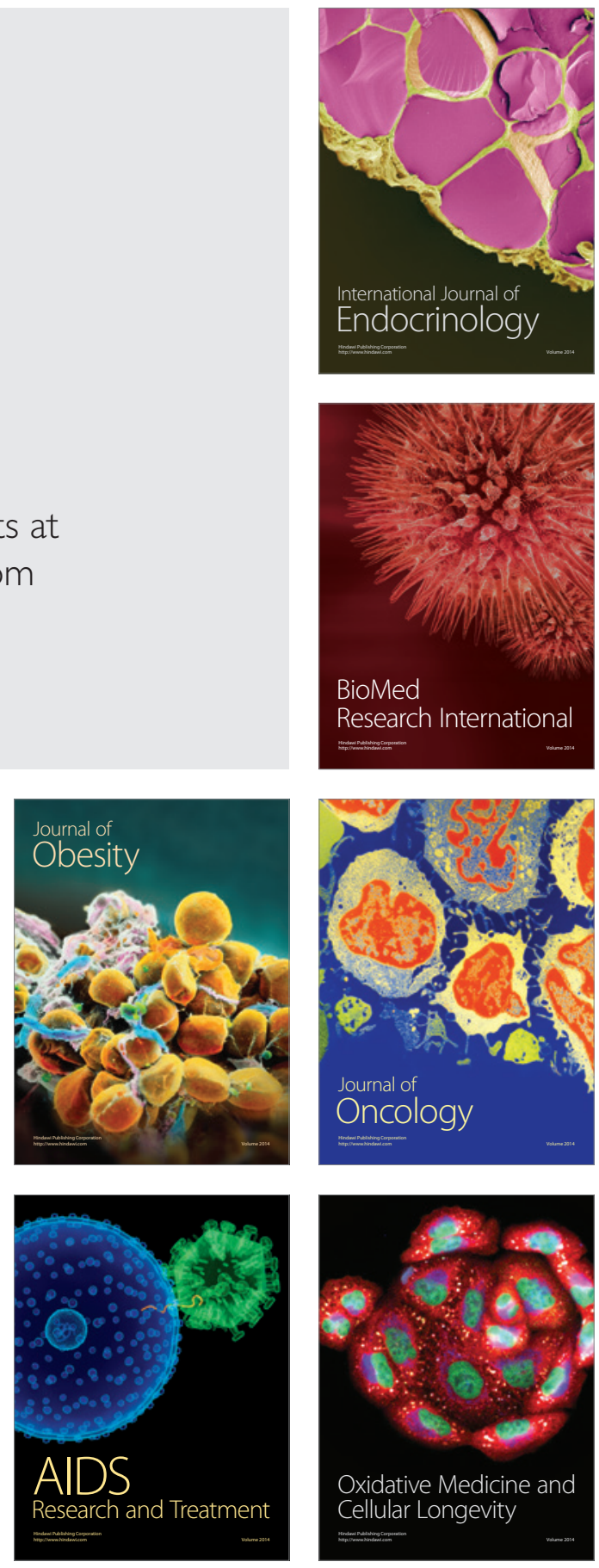